\title{
Optimal Storage Rack Design for a 3-dimensional \\ Compact AS/RS
}

Tho Le-Duc, M.B.M. de Koster and Yu Yugang

\begin{tabular}{|l|l|}
\hline \multicolumn{2}{|l|}{ ERIM REPORT SERIES RESEARCH IN MANAGEMENT } \\
\hline ERIM Report Series reference number & ERS-2006-027-LIS \\
\hline Publication & June 2006 \\
\hline Number of pages & 28 \\
\hline Persistent paper URL & \\
\hline Email address corresponding author & yyugang@rsm.nl \\
\hline Address & Erasmus Research Institute of Management (ERIM) \\
& RSM Erasmus University / Erasmus School of Economics \\
& Erasmus Universiteit Rotterdam \\
& P.O.Box 1738 \\
& 3000 DR Rotterdam, The Netherlands \\
& Phone: $\quad+31104081182$ \\
& Fax: $\quad+31104089640$ \\
& Email: info@erim.eur.nl \\
& Internet: $\quad$ www.erim.eur.nl \\
\hline
\end{tabular}

Bibliographic data and classifications of all the ERIM reports are also available on the ERIM website: www.erim.eur.nl 


\section{ERASMUS RESEARCH INSTITUTE OF MANAGEMENT}

\section{REPORT SERIES}

\section{RESEARCH IN MANAGEMENT}

\begin{tabular}{|l|l|}
\hline \multicolumn{2}{|l|}{ ABSTRACT AND KEYWORDS } \\
\hline Abstract & $\begin{array}{l}\text { In this paper, we consider a newly-designed compact three-dimensional automated storage and } \\
\text { retrieval system (AS/RS). The system consists of an automated crane taking care of movements } \\
\text { in the horizontal and vertical direction. A gravity conveying mechanism takes care of the depth } \\
\text { movement. Our research objective is to analyze the system performance and optimally } \\
\text { dimension of the system. We estimate the crane's expected travel time for single-command } \\
\text { cycles. From the expected travel time, we calculate the optimal ratio between three dimensions } \\
\text { that minimizes the travel time for a random storage strategy. In addition, we derive an } \\
\text { approximate closed-form travel time expression for dual command cycles. Finally, we illustrate } \\
\text { the findings of the study by a practical example. }\end{array}$ \\
\hline Free Keywords & Order picking, Compact storage rack design, AS/RS, Travel time model, Warehousing \\
\hline Availability & $\begin{array}{l}\text { The ERIM Report Series is distributed through the following platforms: } \\
\text { Academic Repository at Erasmus University (DEAR), DEAR ERIM Series Portal } \\
\text { Social Science Research Network (SSRN), SSRN ERIM Series Webpage } \\
\text { Research Papers in Economics (REPEC), REPEC ERIM Series Webpage }\end{array}$ \\
\hline Classifications & $\begin{array}{l}\text { The electronic versions of the papers in the ERIM report Series contain bibliographic metadata } \\
\text { by the following classification systems: } \\
\text { Library of Congress Classification, (LCC) LCC Webpage } \\
\text { Journal of Economic Literature, (JEL), JEL Webpage } \\
\text { ACM Computing Classification System CCS Webpage } \\
\text { Inspec Classification scheme (ICS), ICS Webpage }\end{array}$ \\
\hline
\end{tabular}




\section{Optimal Storage Rack Design for a 3-dimensional Compact AS/RS \\ Tho Le-Duc*, René (M.) B.M. de Koster ${ }^{\S}$, and YU Yugang ${ }^{\S}$}

\section{* Tho Le-Duc (Corresponding author)}

Department of Management of Technology and Innovation

RSM Erasmus University

Burgemeester Oudlaan 50

3062 PA Rotterdam, the Netherlands

Telephone: +31-10-4082920

Fax: +31-10-4089014

Email: tleduc@rsm.nl

§ René (M.) B.M. de Koster

Department of Management of Technology and Innovation

RSM Erasmus University

Burgemeester Oudlaan 50

3062 PA Rotterdam, the Netherlands

Telephone: +31-10-4081719

Fax: +31-10-4089014

Email: rkoster@rsm.nl

\section{$\S$ Yu Yugang}

Department of Management of Technology and Innovation

RSM Erasmus University

Burgemeester Oudlaan 50

3062 PA Rotterdam, the Netherlands

Telephone: +31-10-4081719

Email: yyugang@rsm.nl 


\title{
Optimal Storage Rack Design for a 3-dimensional Compact AS/RS
}

\begin{abstract}
In this paper, we consider a newly-designed compact three-dimensional automated storage and retrieval system (AS/RS). The system consists of an automated crane taking care of movements in the horizontal and vertical direction. A gravity conveying mechanism takes care of the depth movement. Our research objective is to analyze the system performance and optimally dimension of the system. We estimate the crane's expected travel time for single-command cycles. From the expected travel time, we calculate the optimal ratio between three dimensions that minimizes the travel time for a random storage strategy. In addition, we derive an approximate closed-form travel time expression for dual command cycles. Finally, we illustrate the findings of the study by a practical example.
\end{abstract}

Keywords: Order picking; Compact storage rack design; AS/RS; Travel time model; Warehousing;

\section{Introduction}

Although their application is still limited, compact storage systems become increasingly popular for storing products (Van den Berg and Gademann 2000 and $\mathrm{Hu}$ et al. 2005), with relatively low unit-load demand, on standard product carriers. Their advantage is the full automation, making it possible to retrieve and store unit loads around the clock, on a relatively small floor area. In principle, every load can be accessed individually, although some shuffling may be required. They are also used to automatically presort unit loads within the system, so that these loads can rapidly be retrieved when they are needed.

Several compact storage system technologies exist with different handling systems taking care of the horizontal, vertical and depth movements. In this paper, we calculate the travel time and investigate the optimal dimensions for minimizing the travel time under a random storage 
strategy, for a given storage capacity, of the compact storage system as sketched in Figure 1. This system has been designed for several application areas.

The compact storage system consists of a storage/retrieval $(\mathrm{S} / \mathrm{R})$ machine taking care of movements in the horizontal and vertical direction (the $\mathrm{S} / \mathrm{R}$ machine can drive and lift simultaneously). A gravity conveying mechanism takes care of the depth movement. Conveyors work in pairs: unit loads on one conveyor flow to the rear end of the rack, in the neighboring conveyor unit loads flow to the $S / R$ machine. At the backside of the rack, an inexpensive simple elevating mechanism lifts unit loads from the down conveyor to the upper conveyor, one at a time.

\section{[Insert Figure 1 here]}

The innovation of the system is in its cheap construction: no motor-driven parts are used for the conveyors and the construction of the lifting mechanisms is simple as well. The unit loads move by (controlled) gravity. Potential application areas are also innovative. We have studied applications in dense container stacking at a container yard and the Distrivaart project in the Netherlands, where pallets are transported by barge shipping between several suppliers and supermarket warehouses. This project has actually been implemented and has resulted in a fully automated storage system on a barge.

The throughput capacity of the system depends on not only the physical design, the speeds of handling systems used, but also on the dimensions of the system and the storage and retrieval strategy used. We first study single cycles (in fact, we investigate only retrievals, as these are more critical for system performance than storages) under a random storage strategy. This is more or less a worst-case scenario, since in reality pre-sorting is often possible. We also study double cycles, where the storage of a load is followed by retrieval. Although finding the $\mathrm{S} / \mathrm{R}$ machine travel time is not too difficult for the general case compared with 2-dimensinal systems, finding closed-form expressions for the three dimensions that minimize the total expected travel time is more complicated. 
A considerable number of papers analyze AS/RS performance. Most of these papers discuss storage rack dimensions, storage assignment, and $\mathrm{S} / \mathrm{R}$ operational issues. To obtain exact or approximate optimal system performance analytical models and simulation are used. In this section, we review the most recent publications (i.e. mainly articles published after 1995, except for some important earlier ones) concerning AS/RS performance analysis. We discuss the publications based on the system characteristics and solution methods applied. For a general review on the design and control of automated material handling systems, we refer to Johnson and Brandeau (1996). For an overview of travel time models for AS/RS published before 1995, it is advisable to see Sarker and Babu (1995).

- Storage rack dimensions. The storage rack shape may influence the performance of the $\mathrm{AS} / \mathrm{RS}$. It is proven that under the random storage assignment and with a constant $\mathrm{S} / \mathrm{R}$ machine speed, the square-in-time (SIT) rack is the optimal configuration (Bozer and White 1984). However, this is not necessarily true for other storage assignments. Pan and Wang (1996) propose a framework for the dual-command cycle continuous travel-time model under the class-based assignment. The model is developed for SIT racks using a first-come-first-serve (FCFS) retrieval sequence rule. Foley and Frazelle (1991) derive the dual-command travel-time distribution for a SIT rack with uniformly distributed turnover. In a recent paper Park et al. (2005) calculate the distribution of the expected dualcommand travel time and throughput of SIT racks with two storage zones of high and low turnover, respectively. Ashayeri et al. (1996) compute the expected cycle time for an S/R machine where racks can be either SIT or non square-in-time (NSIT). Park et al. (2003) compute the mean and variance of single and dual-command travel times for NSIT racks with turnover-based storage assignment. They also show how to adjust the model if classbased storage assignment is used. In general, AS/RSs have racks of equally-sized cells. However, in some cases, a higher utilization of warehouse storage can be achieved by using unequally sized cells. 
- Storage assignment. Using product turnover-frequency class-based and dedicated storage assignments may lead to a substantial saving on the travel time of the $S / R$ machine compared with a random storage assignment. For a two-class-based storage assignment rack, Kouvelis and Papanicolaan (1995) develop expected command cycle time formulas for both single and dual-command cycles. They also present explicit formulas for the optimal boundary of the two storage areas in the case of single-command cycles. As exact expressions of the throughput are often lengthy and cumbersome, Foley et al. (2004) derive formulas bounding and approximating the throughput of a mini-load system with exponential distributed pick time and either uniform or turnover-based storage assignment. They report that for typical configurations, the worst-case relative error for the bounds is less than $4 \%$.

- $S / R$ machine operational issues. Depending on its number of shuttles, a $\mathrm{S} / \mathrm{R}$ machine can carry out single, dual, and multiple commands in one cycle. With one shuttle, the S/R machine can at most execute two commands (storage and retrieval) in one travel cycle. Most papers study single and dual-command cycles (for example, single-command cycles in Kim and Seidmann 1990, Park et al. 2003a; dual-command cycles in Foley and Frazelle 1991, Pang and Wang 1996, Lee et al. (1999)). By using multiple shuttles, the S/R can perform more than two commands in one travel cycle, and thus the system performance can be enhanced. Meller and Mungwattana (1997) present analytical models for estimating the throughput in multi-shuttle AS/RS. Potrč et al. (2004) present heuristic travel time models for AS/RS with equally-sized cells in height and randomized storage under single- and multi-shuttle systems. Several papers consider different speed models for the $\mathrm{S} / \mathrm{R}$ machine. Most studies assume the $\mathrm{S} / \mathrm{R}$ crane speed is constant. In practice this assumption may not hold (Hwang and Lee (1990)), due to crane acceleration and deceleration (especially for small racks). Chang et al. (1995) propose a S/R machine travel time model by considering the speed profiles that exist in real-word applications. They 
consider the system under random storage assignment, single and dual-command cycles. Chang and Wen (1997) extend this travel time model to investigate the impact on the rack configuration. The optimal rack configuration for single-command cycles still appears to be SIT, whereas this may not be the case for dual-command cycles. Wen et al. (2001) adjust the travel time model of Chang et al. (1995) for class-based and turnover-based storage assignment.

- Solution approach. Most of the travel time models are developed based on statistical analysis and simulation (for example, Hausman et al. 1976, Graves et al. 1977, Bozer and White 1984, Foley et al. 2002, 2004). Lee (1997) uses a single-server model with two queues to estimate the throughput of a mini-load system, where the cycle times are assumed to be independent, identical, and exponentially distributed (iid) random variables, while requests arrive according to a Poisson process. Simulation results in this study show that the method performs well and can be easily adapted for other AS/RS. However, Hur et al. (2004) claim that the exponential distribution of travel times does not reflect the dynamic aspect of the system. They propose to use an M/G/1 queuing model (also with a single server and two queues). According to their computational results, the proposed approach gives satisfactory results with high accuracy. Park et al. (1999) study an end-ofaisle order-picking system with inbound and outbound buffer positions (a mini-load system with a horse-shoe front-end configuration). They model the system as a two-stage cyclic queuing system consisting of one general and one exponential server queue with limited capacity. They assume that the $\mathrm{S} / \mathrm{R}$ machine always executes dual-command cycles and the dual-command cycle times are independent of each other. They obtain closed form expressions for the stationary probability and the throughput of the system. To compute the mini-load system throughput, the distribution of order arrivals is needed (usually the pick time distribution is assumed to be exponential or uniform, see for example Bozer and White (1990), Foley and Frazelle (1991), Bozer and White (1996)). 
However, this information is not completely available at the design phase (only partial information is known). Foley et al. (2002) determine upper and lower throughput bounds for mini-load systems under different partial information types: no information, mean only, and NBUE (i.e. New Better than Used in Expectation, roughly it means that the mean pick time of a partially processed bin is smaller than the mean pick time from a new bin).

In the above-mentioned publications, only two travel directions are considered (vertical and horizontal). However, compact storage systems exist in which unit loads can travel in three orthogonal directions, i.e. in vertical, horizontal, and cross-aisle direction, by using different material handling systems (like $\mathrm{S} / \mathrm{R}$ cranes, conveyors, shuttles, or elevators). Park and Webster (1989b) propose a conceptual model that can help a warehouse planner in the design of 3-dimensional pallet storage systems. Park and Webster (1989a) deal with the problem of finding a rule for assigning product turnover classes to rack locations to minimize the expected travel time. In these publications, however, the rack dimensions are given or, in other words, the problem of determining the optimal rack dimensions is neglected. We have not found any literature on travel time estimation and/or optimal system dimensioning for 3-dimensional storage systems. Our main contributions are the derivation of such a travel-time model and using this to dimension a three-dimensional AS/RS.

The remainder of the paper is organized as follows. In the next section, we give problem assumptions, notations, and propose our model for the 3-dimensional rack system with single commands. In Section 3, we find the optimal rack dimensions that minimize the singlecommand travel time for the general NSIT rack and compare the results with those of SIT racks. We analyze the effect of fixing some dimension in the subsections. In Section 4 we extend the results to dual-command cycles. We are able to develop approximate closed-form expression for the expected travel time and can use this to dimension the racks. In Section 5 a 
numerical study illustrates the results found in some special cases. Finally, we conclude and propose some potential directions for future research in Section 6.

\section{Assumptions and analytical model}

We start with the assumptions and then present the travel-time model for single command cycles.

\subsection{Assumptions}

We study the system sketched in figure 1 and make the following assumption, which are commonly used in AS/RS (see also Bozer and White 1984, 1990, 1996, Ashayeri et al. 2002, Foley et al. 2004):

- The $\mathrm{S} / \mathrm{R}$ machine is capable of simultaneously moving in vertical and horizontal direction at constant speeds. Thus, the travel time required to reach any location in the rack (or a storage conveyor pair in our case) is approximated by the Tchebyshev metric.

- The rack is considered to have a continuous rectangular pick face, where the depot (also: I/O point) is located at the lower left-hand corner (see figure 1).

Besides these common assumptions, we use the following specific assumptions for our travel time model:

- The conveyor can move loads in an orthogonal depth dimension, independent of the S/R machine movement.

- The S/R machine operates on a single-command basis (multiple stops in the aisle are not allowed). We consider retrievals only. We later relax this assumption and also study dualcommand cycles.

- The total storage space, the speed of the conveyor, as well as the S/R machine's speed in the horizontal and vertical direction, are known. Constant velocities are assumed for the 
horizontal, vertical and depth movement: no acceleration and deceleration effects. Such effects might be included in the pick-up/ deposit times.

- We use random storage. That is, any point within the pick face is equal likely to be selected for storage or retrieval.

- The pick-up and deposit (P/D) time for a given load is known and constant.

\subsection{Notations and model}

The length $(L)$, the height $(H)$ of the rack, and the perimeter of the conveyor (with length $2 \mathrm{~S}$ ) form three orthogonal dimensions of the system. The speed of the conveyor and the S/R machine's speed in the horizontal and vertical direction, are denoted by $s_{c}, s_{h}$, and $s_{v}$ respectively.

Without loss of generality, we suppose that the travel time to the end of the rack is no less than the travel time to the highest location in the rack: $\frac{H}{S_{v}} \leq \frac{L}{S_{h}}$. To standardize the system, we define the following quantities.

$t_{c}=\frac{2 * S}{S_{c}}:$ length (in time) of the conveyor.

$t_{h}=\frac{L}{s_{h}}: \quad$ length (in time) of the rack.

$t_{v}=\frac{H}{S_{v}}: \quad$ height (in time) of the rack.

$T=\max \left\{t_{h}, t_{v}, t_{c}\right\}$

$b=\min \left\{\frac{t_{h}}{T}, \frac{t_{v}}{T}, \frac{t_{c}}{T}\right\}$. Note that $0 \leq b \leq 1$ and $b=1$ if and only if $t_{h}=t_{v}=t_{c}$.

$a$ is the remaining element (besides $b$ and 1) of the set $\left\{\frac{t_{h}}{T}, \frac{t_{v}}{T}, \frac{t_{c}}{T}\right\}$, thus $0<b \leq a \leq 1$. 
If $t_{h}=t_{v}$ we call the rack square-in-time (SIT). For determining the optimal dimensions of the rack, we suppose that $2 * H^{*} L^{*} S$ is a constant. As a result $t_{h} t_{v} t_{c}=V$ is also a constant ( $V$ can be considered as the system storage capacity, in cubic time units).

Assume that the retrieval location is represented by $(x, y, z)$ where $x, y$ and $z$ refer to the movement dimensions on the directions of the $\mathrm{S} / \mathrm{R}$ machine or conveyor. By definition, we let the longest dimension refer to the z-direction/axis, the shortest dimension to the $y$ dimension/axis and the remaining medium dimension to the $\mathrm{x}$-direction/axis. We can see that the S/R machine's retrieval time consists of the following components.

- Time needed for the $\mathrm{S} / \mathrm{R}$ machine to go from the depot to the pick position and to wait for the pick to be available at the pick position (if the conveyor circulation time is larger than the travel time of the $\mathrm{S} / \mathrm{R}$ machine), $W$. In other words, $W$ is the maximum of the following quantities:

- time needed to travel horizontally from the depot to the pick position,

- time needed to travel vertically from the depot to the pick position,

- time needed for the conveyor to circulate the load from its current position to the pickup position.

- Time needed for the $\mathrm{S} / \mathrm{R}$ machine to return to the depot, $U$

- Time needed for picking up and dropping off the load, $c$, which is a constant.

Hence, the expected retrieval time can be expressed as follows: $E(W)+E(U)+c$ and the expected $\mathrm{S} / \mathrm{R}$ machine travel time equals

$$
E S C=E(W)+E(U)
$$

As proven by Bozer and White (1984), in the case of a 2-dimensional rack, the travel time from a random pick location to the depot can be calculated as:

$$
E(U)=\left(\frac{\beta^{2}}{6}+\frac{1}{2}\right) t_{h},
$$


where $\beta=\frac{t_{v}}{t_{h}}(\beta \leq 1)$ is the shape factor of the rack (recall that we assume $t_{h} \geq t_{v}$ ).

Let $F(w)$ denote the probability distribution function that $W$ is less than or equal to $w$. The $(X, Y, Z)$ coordinates are independently randomly generated along the $x, y$ and $z$-axes, where, by our definition of axes choice: $0<X \leq a, 0<Y \leq b$ and $0<Z \leq 1$ (that is, we consider the 'normalized' rack). Similar to the case of 2-dimensional racks (see Bozer and White (1984)), we have:

$$
F(w)=P(W \leq w)=P(X \leq w) \cdot P(Y \leq w) \cdot P(Z \leq w)
$$

Furthermore, as we use randomized storage; the location coordinates are uniformly distributed. Therefore,

$$
\begin{aligned}
& P(Z \leq w)=w, \text { with } 0 \leq w \leq 1 \\
& P(X \leq w)= \begin{cases}w / a & \text { if } 0 \leq w \leq a \\
1 & \text { if } a<w \leq 1\end{cases} \\
& P(Y \leq w)=\left\{\begin{array}{ll}
w / b & \text { if } 0 \leq w \leq b \\
1 & \text { if } b<w \leq 1
\end{array},\right.
\end{aligned}
$$

Hence,

$$
\begin{gathered}
F(w)= \begin{cases}w^{3} / a b & \text { if } 0 \leq w \leq b \\
w^{2} / a & \text { if } b<w \leq a \\
w & \text { if } a<w \leq 1\end{cases} \\
\Rightarrow f(w)= \begin{cases}3 w^{2} / a b & \text { if } 0 \leq w \leq b \\
2 w / a & \text { if } b<w \leq a \\
1 & \text { if } a<w \leq 1\end{cases}
\end{gathered}
$$

Therefore,

$$
\begin{aligned}
& E(W)=T \int_{w=0}^{1} f(w) w d w=T\left(\int_{w=0}^{b} \frac{3 w^{3}}{a b} d w+\int_{w=b}^{a} \frac{2 w^{2}}{a} d w+\int_{w=a}^{1} w d w\right) \\
& \Rightarrow E(W)=T\left(\frac{b^{3}}{12 a}+\frac{a^{2}}{6}+\frac{1}{2}\right)
\end{aligned}
$$


From (1), (2) and (6), it is possible now to find the single-command travel time if we know the relative magnitude of each dimension compared to the others (i.e. which one is the longest, shortest). The optimal 3-dimensional ratio of the rack can be determined by the following general model (denoted as GM):

\section{Model GM:}

$$
\begin{aligned}
\text { Minimize } & E S C(a, b, T)=E(U)+E(W)=\left(\frac{\beta^{2}}{6}+\frac{1}{2}\right) t_{h}+T\left(\frac{b^{3}}{12 a}+\frac{a^{2}}{6}+\frac{1}{2}\right) \\
\text { subject to } & a b T^{3}=V \\
\beta & = \begin{cases}b / a & \text { if } t_{c}=T \\
b & \text { if } t_{c}=a T \\
a & \text { if } t_{c}=b T\end{cases} \\
t_{h} & = \begin{cases}a T & \text { if } t_{c}=T \\
T & \text { if } t_{c}=a T \\
T & \text { if } t_{c}=b T\end{cases}
\end{aligned}
$$

where $V$ is a positive constant, $T>0$ and $0<b \leq a \leq 1$.

When the optimal solution, $a$ and $b$, of model GM has been obtained, the ratio between the three dimensions which minimizes the expected travel time can be determined. In order to find this optimal ratio, we distinguish the following three cases: (1) $t_{v}: t_{h}: t_{c} \equiv b: a: 1$, if $t_{c}=T ;(2)$ $t_{v}: t_{h}: t_{c} \equiv b: 1: a$ if $t_{c}=a T$; (3) $t_{v}: t_{h}: t_{c} \equiv a: 1: b$ if $t_{c}=b T$ respectively. If we can find the optimal solution for each of these cases, the one with minimal ESC gives the overall optimal solution of model GM. To facilitate the analysis of these three cases, we distinguish two situations: general racks (section 3) and racks with one or more dimensions fixed, in particular cubic-in-time racks (section 4).

\section{Optimal dimensions for the compact rack}

For 2-dimensional racks, it is known that the expected travel time will be minimized if the rack is SIT (Bozer and White (1984)). In subsection 3.1, we determine the optimal ratio between the three dimensions in horizontal, vertical, and deep directions. We show that it is SIT, but not cubic-in-time. Then in subsection 3.2, we study the effect of fixing some dimensions or ratios 
between dimensions. We compare the overall results of subsection 3.1 with those of cubic-intime racks.

\subsection{General unrestricted racks (NSIT)}

According to model GM, we make a distinction between the following cases:

- the conveyor's length is the longest dimension (NSIT_CL),

- the conveyor's length is the medium dimension (NSIT_CM),

- the conveyor's length is the shortest dimension (NSIT_CS).

If the conveyor's length is the longest dimension then we have: $T=t_{c}, t_{h}=a t_{c}$, $t_{v}=b t_{c}\left(\right.$ thus $\left.\beta=\frac{b}{a}\right)$ and $a b t_{c}^{3}=V$. From equations (3)-(5), it can be seen that the $x, y$-axes refer to the $\mathrm{S} / \mathrm{R}$ machine's horizontal and vertical directions, and the $\mathrm{z}$-axis refers to the conveyor's direction.

From model GM, we have:

$$
E S C_{\text {NSIT_CL }}=\left(\frac{b^{3}+2 b^{2}}{12 a}+\frac{a^{2}}{6}+\frac{a}{2}+\frac{1}{2}\right) t_{c}
$$

Similarly, if the conveyor's length is the medium dimension: $T=t_{h}, t_{v}=b t_{h}$, (thus $\beta=b), t_{c}=a t_{h}, a b t_{h}^{3}=V$, and the $x$ axis refers to the conveyor's direction, we have:

$$
E S C_{N S I T_{-} C M}=\left(\frac{b^{3}}{12 a}+\frac{a^{2}}{6}+\frac{b^{2}}{6}+1\right) t_{h}
$$

Finally, if the conveyor is the shortest dimension: $T=t_{h}, t_{v}=a t_{h}$, (thus $\left.\beta=a\right), t_{c}=b t_{h}$, $a b t_{h}^{3}=V$, and the $y$ axis refers to the conveyor's direction, we have:

$$
E S C_{\text {NSIT_CS }}=\left(\frac{b^{3}}{12 a}+\frac{a^{2}}{3}+1\right) t_{h}
$$

Since $E S C_{\text {NSIT_CS }}-E S C_{\text {NSIT_CM }_{-}}=\left(a^{2}-b^{2}\right) / 6 \geq 0$, we obtain from (9) and (10): $E S C_{\text {NSIT_CM }}$ $\leq$ ESC $_{\text {NSIT_CS }} \forall(0<b \leq a \leq 1, V>0)$. Apparently, systems where the conveyor is the shortest 
or medium dimension cannot provide a better solution compared to the system where the conveyor is the longest dimension. For this reason, from now on, we can ignore $E_{S C C_{N S I T} C S}$.

According to model GM, the problem of finding the optimal $E S C_{N_{N I T} C L}$ turns out to be the following constrained-optimization problem:

$$
\begin{aligned}
& \text { Minimize } \quad f_{3}\left(a, b, t_{c}\right)=\left(\frac{b^{3}+2 b^{2}}{12 a}+\frac{1}{6} a^{2}+\frac{a}{2}+\frac{1}{2}\right) t_{c} \\
& \text { subject to } \quad D=\left\{\left(a, b, t_{c}\right) \mid a b t_{c}{ }^{3}=V, 0<b<a \leq 1, t_{c} \geq 0, V>0\right\}
\end{aligned}
$$

From $a b t_{c}^{3}=V$ in (12), we have

$$
t_{c}=\sqrt[3]{\frac{V}{a b}} .
$$

Because variables $a, b>0$ and constant $V>0$, we have $t_{c}=\sqrt[3]{\frac{V}{a b}}>0 . t_{c} \geq 0$ is a redundant constraint in (12), which can be omitted in the following optimization problems.

Substituting (13) into (11), we obtain

$$
f_{3}(a, b)=\left(\frac{b^{3}+2 b^{2}}{12 a}+\frac{a^{2}}{6}+\frac{a}{2}+\frac{1}{2}\right) \sqrt[3]{\frac{V}{a b}} .
$$

Considering $V$ is a positive constant, the problem, described by (11) and (12), turns out to be the following equivalent constrained-optimization problem (denoted as $E S C_{N S I T_{-} C L_{-} E}$ ):

subject to

$$
\text { Minimize } \bar{f}_{3}(a, b)=\left(\frac{b^{3}+2 b^{2}}{12 a}+\frac{a^{2}}{6}+\frac{a}{2}+\frac{1}{2}\right)(a b)^{-\frac{1}{3}} \text {. }
$$

$$
D=\{(a, b) \mid 0<b \leq a \leq 1\}
$$

It is easy to understand that the optimal variable value $(a, b)$ for problem $E S C_{N S I T_{-} C L_{-} E}$ is the same as that of the original problem described by (11) and (12), and the relationship between the two optimal objective function values is that $f_{3}^{*}(a, b)=\bar{f}_{3}^{*}(a, b) \sqrt[3]{V}$.

Since 


$$
\begin{aligned}
& \frac{\partial^{2} \bar{f}_{3}(a, b)}{\partial a^{2}}=\frac{6 a-3 a^{2}+5 a^{3}+7 b^{2}(2+b)}{27 a^{10 / 3} b^{1 / 3}}>0 \text { and } \\
& \left|\begin{array}{ll}
\frac{\partial^{2} \bar{f}_{3}(a, b)}{\partial a^{2}} & \frac{\partial^{2} \bar{f}_{3}(a, b)}{\partial a \partial b} \\
\frac{\partial^{2} \bar{f}_{3}(a, b)}{\partial b \partial a} & \frac{\partial^{2} \bar{f}_{3}(a, b)}{\partial b^{2}}
\end{array}\right| \\
= & \frac{45 a^{2}+36 a^{3}+30 a^{4}+12 a^{5}+5 a^{6}+192 a b^{2}+12 a^{2} b^{2}+4 a^{3} b^{2}+168 a b^{3}-48 a^{2} b^{3}+32 a^{3} b^{3}-40 b^{4}+20 b^{5}+8 b^{6}}{972 a^{14 / 3} b^{8 / 3}} \\
= & \frac{45 a^{2}+36 a^{3}+30 a^{4}+12 a^{5}+5 a^{6}+\left(192 a b^{2}-40 b^{4}\right)+12 a^{2} b^{2}+4 a^{3} b^{2}+\left(168 a b^{3}-48 a^{2} b^{3}\right)+32 a^{3} b^{3}+20 b^{5}+8 b^{6}}{972 a^{14 / 3} b^{8 / 3}}>0,
\end{aligned}
$$

and the constraints in the feasible area $D=\{(a, b) \mid 0<b<a \leq 1\}$ are linear, the optimization problem $E S C_{N^{\prime} I T_{-} C L_{-} E}$ is a convex non-linear programming problem, and its local optimum is a global one. The method to obtain a local optimal solution of the problem is to solve the KuhnTucker the conditions, which are the necessary and sufficient conditions to obtain the overall optimal solution of $E S C_{N S I T_{-} C L_{-} E}$. Let $\left(a^{*}, b^{*}\right)$ denote the critical point that satisfies the KuhnTucker condition of the equivalent constrained-optimization problem, $E S C_{N_{N I T} C L_{-} E}$. Because

$$
\begin{aligned}
& \frac{\partial \bar{f}_{3}(a, b)}{\partial a}=\frac{5 a^{* 3}+6 a^{* 2}-3 a^{*}-2 b^{* 2}\left(2+b^{*}\right)}{18 a^{* 7 / 3} b^{* 1 / 3}}, \frac{\partial \bar{f}_{3}(a, b)}{\partial b}=\frac{b^{* 2}\left(5+4 b^{*}\right)-a^{* 3}-3 a^{* 2}-3 a^{*}}{18\left(a^{*} b^{*}\right)^{4 / 3}}, \text { we have: } \\
& \frac{5 a^{* 3}+6 a^{* 2}-3 a^{*}-2 b^{* 2}\left(2+b^{*}\right)}{18 a^{* 7 / 3} b^{* 1 / 3}}+\gamma_{1}^{*}-\gamma_{2}^{*}=0, \\
& \frac{b^{* 2}\left(5+4 b^{*}\right)-a^{* 3}-3 a^{* 2}-3 a^{*}}{18\left(a^{*} b^{*}\right)^{4 / 3}}+\gamma_{2}^{*}-\gamma_{3}^{*}=0, \\
& \gamma_{1}^{*}\left(1-a^{*}\right)=0, \\
& \gamma_{2}^{*}\left(a^{*}-b^{*}\right)=0, \\
& \gamma_{3}^{*} b^{*}=0, \\
& \gamma_{1}^{*}, \gamma_{2}^{*}, \gamma_{3}^{*} \geq 0,
\end{aligned}
$$

where $\gamma_{1}^{*}, \gamma_{2}^{*}, \gamma_{3}^{*}$ are Lagrangian multipliers in broad sense.

The solution of (17) can be obtained by using numerical methods, such as NewtonRaphson, embedded in a general solver (for example Lingo), or by analytical methods. Here we use Mathematica 5.0, and obtain: $\gamma_{1}^{*}=\gamma_{2}^{*}=\gamma_{3}^{*}=0, a^{*}=b^{*}=\sqrt{10} / 3-1 / 3 \approx 0.72$. 
Substituting $a^{*}=b^{*}=0.72$ into $(15)$, we have $\bar{f}_{3}^{*}\left(a^{*}, b^{*}\right)=1.38$, and $E S C_{\text {NSIT_CL }}^{*}=1.38 \sqrt[3]{V}$.

For $E S C_{\text {NSIT_CM }_{-}}$, we obtain, with similar methods: $a^{*}=1, b^{*}=0.90$, and $E S C_{N_{S I T+C M}}^{*}=1.41 \sqrt[3]{V}$

In conclusion, for the general rack, we can formulate:

Proposition 1 Given a 3-dimensional rack with a total storage capacity $V$, the expected travel time of the $S / R$ machine will be minimized if $t_{v}: t_{h}: t_{c} \equiv 0.72: 0.72: 1$ and the optimal expected travel time is $1.38 \sqrt[3]{V}$

\subsection{Effect of fixing dimensions}

As shown above, if all three dimensions are 'open', we can find the optimal ratio that minimizes the expected travel time. However, in many real-life situations, like the Distrivaart project (see section 1), it is impossible to freely adjust all dimensions, due to space limitations and equipment standardizations. The previous analysis can also be used to solve the problem with space restrictions. If two dimensions are fixed, then the problem is trivial as all dimensions are defined (given that we know the total system's storage capacity). We here consider two special situations: (1) a SIT rack when the conveyor length is the shortest (SIT_CS) and (2) one dimension is fixed.

The SIT_CS rack

From the analysis in subsection 3.1 we know the optimal solution in this case leads to a longer expected travel times than that of SIT_CL. Here we compare the optimal results of SIT_CS with the results of section 3.1 .

For SIT_CS racks, we have $T=t_{h}=t_{v}, \beta=1, t_{c}=b t_{h}, a=1$, and $b t_{h}{ }^{3}=V$. From (3)-(5), it can be seen that $x, z$ refer to the $\mathrm{S} / \mathrm{R}$ machine's vertical and horizontal directions respectively, and $y$ refers to the conveyor's direction. According to model GM, the problem turns out to be the following constrained-optimization problem: 


$$
\begin{array}{ll}
\text { Minimize } & f_{\text {SIT_CS }}\left(b, t_{h}\right)=\left(\frac{b^{3}}{12}+\frac{4}{3}\right) t_{h} \\
\text { subject to } & D=\left\{\left(b, t_{h}\right) \mid b t_{h}^{3}=V, 0<b \leq 1, t_{h} \geq 0\right\}
\end{array} \text {. }
$$

Similar to the analysis in section 3.1 , the optimal solution can be analytically obtained with $b=1, t_{v}=t_{h}=t_{c}=\sqrt[3]{V}$, and the optimal expected travel time is $E S C_{S I T_{-} C S}^{*}=1.42 \sqrt[3]{V}$. Apparently, $E S C_{\text {cubic_in_time }}^{*}=E S C_{S I T_{-} C S}^{*}$. We conclude:

"Given an SIT rack with a total storage capacity $V$ and provided that the conveyor's length $t_{c}$ is the shortest dimension, the expected travel time of the $S / R$ machine will be minimized if $t_{v}: t_{h}: t_{c} \equiv 1: 1: 1$ (cubic-in-time) and the optimal travel time is $1.42 \sqrt[3]{V}$,

The reason that the cubic-in-time rack is not optimal overall is that the travel time consists of two components (see section 2.2). The travel time from the depot to the pick location depends on the movement times on all three directions, but the time needed to go back to the depot depends only on the vertical and horizontal travel time.

Figure 2 shows the optimal travel times for SIT and NSIT racks for varying rack sizes. The differences between the overall optimal value and the optima obtained with some restrictions on the dimensions are only slight. The difference between the optimal cubic-intime configuration and the overall optimal one is:

$$
[(1.42 \sqrt[3]{V}-1.38 \sqrt[3]{V}) / 1.38 \sqrt[3]{V}] * 100 \% \approx 2.90 \%
$$

[Insert Figure 2 here]

\section{The rack with one dimension fixed}

If only one dimension is fixed, we can still adjust the others to reduce the estimated travel time. Clearly, the resulting optimal travel time can not be shorter than the 'overall' optimum (when we have three 'open' dimensions). Using model GM, it is straightforward in this case to determine the expected travel time of the $\mathrm{S} / \mathrm{R}$ machine. Figure 3 shows the optimal expected travel time for different given values of the conveyor's length $\left(t_{c}\right)$, the rack's length $\left(t_{h}\right)$, and 
the rack's height $\left(t_{v}\right)$. From this figure, we can easily see the effect of fixing one dimension.

For example, if the conveyor length is fixed, say if $t_{c}=2 \sqrt[3]{V}(200 \%$ of $\sqrt[3]{V})$, at best we can design a system with an expected travel time of $1.53 \sqrt[3]{V}$ (time units), while the 'overall global' optimum, $1.38 \sqrt[3]{V}$, is achieved for $t_{c}=1.24 \sqrt[3]{V}$. Similar results hold when the rack's length or heights are fixed (in time).

\section{[Insert Figure 3 here]}

\section{Extension to dual command cycles}

Until now, we have considered single-command cycles only: the crane can only either pick up or drop one load per cycle. In many cases, the crane can combine a storage and retrieval in one cycle: Starting at the I/O station, the crane carries a load to the storage position (denoted by $\left.\left(X_{1}, Y_{1}, Z_{1}\right)\right)$. After putting away the load, it moves to the retrieval position (denoted by $\left.\left(X_{2}, Y_{2}, Z_{2}\right)\right)$ and retrieves and brings back another to the I/O point. In this section, we extend the travel time models developed for the single-command cycle to a dual-command cycle. All assumptions made before are kept unchanged expect that there two commands in one travel cycle. The $x, y$, and $z$-axes are defined as before.

The cycle time of the S/R machine (EDC) consists of the following components:

- Time needed to go to the storage position and waiting time for the conveyor to convey an empty location for the storage load, if any. We assume the rotation time to reveal an empty location has the same probability distribution function as the rotation time for a retrieval load to be at the pick position. Consequently, this time component is the same as in case of the single-command cycles: $W=\max \left\{X_{1}, Y_{1}, Z_{1}\right\}$ (see Equation (6)). 
- $\quad$ Time needed for picking up and dropping off a load, $c$, where $c$ is a constant, which is here assumed to be zero to simplify the analysis. According to Hausman et al. (1976) these times are small compared to total crane utilization time.

- Travel time from the storage point to the retrieval point: D. This is the travel time between two randomly selected points. As shown in Bozer and White (1984):

$$
\begin{aligned}
& f_{D}(d)= \begin{cases}=\frac{2-2 d}{2 d / \beta-d^{2} / \beta^{2}}+\frac{2 d-d^{2}}{2 / \beta-2 d / \beta^{2}} & \text { if } 0 \leq d \leq \beta \\
=2-2 \beta & \text { if } \beta<d \leq 1\end{cases} \\
& E(D)=\left(\frac{1}{3}+\frac{\beta^{2}}{6}-\frac{\beta^{3}}{30}\right) t_{v},
\end{aligned}
$$

where $0<\beta \leq 1$ is the shape factor of the rack.

- The waiting time, $T_{w}$, that may occur if the rotation time of the conveyor carrying the retrieval load $R$, is longer than the time the $\mathrm{S} / \mathrm{R}$ machine needed to be available at the retrieval position: $T_{w}, T_{w}=\max \{0, R-(W+D)\}$

- Travel time needed for returning to the $\mathrm{I} / \mathrm{O}$ point, $U$. This time component is identical to the case of retrieval cycles and $E(U)$ can be calculated by Equation (2)(2).

As the conveyor with the retrieval load can be activated at the moment the $\mathrm{S} / \mathrm{R}$ machine picks up a load to leave the I/O point, $P(W+D \leq R)$ will be small for realistically sized racks (even more when $c \neq 0)$. Also, in practice, $t_{c}$ has to be restricted for technical reasons. We here therefore assume that $T_{w}$ can be ignored.

The expected dual-command travel time can now be approximately expressed as follows:

$$
E D C=E(W)+E(U)+E(D)
$$

As in the case of single-command cycles, we make a distinction between the following situations:

- the conveyor's length is the longest dimension $\left(E D C_{C L}\right)$,

- the conveyor's length is the medium dimension $\left(E D C_{C M}\right)$, 
- the conveyor's length is the shortest dimension $\left(E D C_{C S}\right)$.

If the conveyor's length is the longest dimension, we have $T=t_{c}, t_{h}=a t_{c}, t_{v}=b t_{c}, \beta=\frac{b}{a}$, and $a b t_{c}^{3}=V$, and the z-axis refers to the conveyor's direction. We have:

$E D C_{C L}=\left(\frac{1}{2}+\frac{5 a}{6}+\frac{a^{2}}{6}+\frac{b^{2}}{3 a}-\frac{b^{3}}{30 a^{2}}+\frac{b^{3}}{12 a}\right) \sqrt[3]{\frac{V}{a b}}$

If the conveyor's length is the medium dimension, we have $T=t_{h}, t_{v}=b t_{h}, t_{c}=a t_{h}$, (thus $\beta=b$ ), and $a b t_{h}^{3}=V$, and the $x$-axis refers to the conveyor's direction. We find:

$E D C_{C M}=\left(\frac{4}{3}+\frac{a^{2}}{6}+\frac{b^{2}}{3}-\frac{b^{3}}{30}+\frac{b^{3}}{12 a}\right) \sqrt[3]{\frac{V}{a b}}$

If the conveyor is the shortest dimension: $T=t_{h}, t_{v}=a t_{h}$, (thus $\left.\beta=a\right), t_{c}=b t_{h}$ and $a b t_{h}^{3}=V$.

The $y$-axis refers to the conveyor's direction. It then follows:

$E D C_{C S}=\left(\frac{4}{3}+\frac{a^{2}}{2}-\frac{a^{3}}{30}+\frac{b^{3}}{12 a}\right) \sqrt[3]{\frac{V}{a b}}$.

Because

$E D C_{C S}-E D C_{C M}=\frac{\left(10 a^{2}-a^{3}\right)-\left(10 b^{2}-b^{3}\right)}{30} \sqrt[3]{\frac{V}{a b}}=\frac{(a-b)\left(10 a+10 b-a^{2}-b^{2}-a b\right)}{30} \sqrt[3]{\frac{V}{a b}} \geq 0, \quad$ we have $\quad E D C_{C S} \geq E D C_{C M} \quad$ Moreover, because $E D C_{C M}-E D C_{C L}$ $=\frac{(1-a)\left(25 a^{2}-10 a b^{2}+b^{3}+a b^{3}\right)}{30 a^{2}} \sqrt[3]{\frac{V}{a b}} \quad=\frac{(1-a)\left(15 a^{2}+b^{3}+a b^{3}\right)}{30 a^{2}} \sqrt[3]{\frac{V}{a b}} \quad \geq 0, \quad$ we $\quad$ have $E D C_{C L} \leq E D C_{C M}$. As a result, the expected dual-command travel time will be minimized when the conveyor's length is the longest dimension.

With some effort, in a fashion similar to section 3.1, $E D C_{C L}$ can be proven to be a convex function optimal the optimal solution $a^{*}=b^{*}=0.58, t_{c}^{*}=1.43 \sqrt[3]{V}$ and $E D C_{C L}^{*}=1.78 \sqrt[3]{V}$. The optimal $t_{h}^{*}$ and $t_{v}^{*}$ can be obtained: $t_{h}^{*}=t_{v}^{*}=a^{*} \times t_{c}^{*}=0.84 \sqrt[3]{V}$. It can be seen that the expected conveyor's rotation time of the conveyor carrying the retrieval load, $E\left(Z_{2}\right)=t_{c}^{*} / 2=0.76 \sqrt[3]{V}$ is 
much less than the expected travel time from the $\mathrm{I} / \mathrm{O}$ point to the retrieval position $E(W)+E(D)=1.22 \sqrt[3]{V}$

\section{An example}

As an illustrating example, assume that we have to design a 3-dimensional compact system that can store 2000 pallets (other data are given in Table 1), with a layout as shown in Figure 1.

[Insert Table 1 here]

We apply the theorem of Section 3 to calculate the optimal rack dimensions. We have: $t_{c}^{*}=1.24 \sqrt[3]{V}=1.24 \sqrt[3]{0.5 \times 0.5 \times 2.17 \times 2000}=12.78$ (seconds), $t_{h}^{*}=t_{v}^{*}=0.72 t_{c}^{*}=9.21 \quad$ (seconds) and the optimal travel time is $1.38 \sqrt[3]{V}=1.38 \sqrt[3]{0.5 \times 0.5 \times 2.17 \times 2000}=14.20$ ( seconds ) for the given storage capacity $V=\sqrt[3]{0.5 \times 0.5 \times 2.17 \times 2000}=1085\left(\right.$ seconds $\left.^{3}\right)$. The rack dimensions must be multiples of the pallet's dimensions. Therefore, we choose the 'practical optimal' dimensions such that they are as close as possible to the corresponding optimal dimensions found and that they result in a system with a storage capacity of at least 2000 pallets (the required capacity). We obtain the practical approximate optimal dimensions: $9 \times 8.68 \times 14$ (seconds) (i.e. $18 \times 4 \times 28$ in numbers of the pallets) in horizontal, vertical and depth dimensions respectively with an optimal expected travel time of 14.24 (seconds). This deviates (14.24$14.20) / 14.20 \times 100 \%=0.27 \%$ from the theoretical optimal solution. The real rack capacity is 2016 pallets.

\section{Concluding remarks}

In this paper, we discuss a 3-dimensional compact system originating from the Distrivaart project that consists of rotating conveyors and an $\mathrm{S} / \mathrm{R}$ machine. Although our method was inspired by this real-world application, it may be adapted to other systems consisting of an $S / R$ machine combined with an independent material handling systems moving loads in the depth 
dimension. We extend Bozer and White's method for 2-dimensional rack systems to find the expected load retrieval time (or the single-command travel time of the $\mathrm{S} / \mathrm{R}$ machine). We found:

- For a given 3-dimensional compact AS/RS (mentioned above) with a total storage capacity $V$, the optimal rack dimensions are $t_{v}=t_{h}=0.90 \sqrt[3]{V}, t_{c}=1.24 \sqrt[3]{V}$, and the optimal travel time is $1.38 \sqrt[3]{V}$. Equivalently, the optimal ratio between three dimensions is $t_{v}: t_{h}: t_{c} \equiv 0.72: 0.72: 1$.

- The cubic-in-time system (i.e. all dimensions are equal in time) is not the optimal configuration (as we might think intuitively). However, it is a good alternative configuration for the optimal one as the resulting expected travel time is only about $3 \%$ off the optimum. This is in line with the findings by Rosenblatt and Eynan (1989) and Chang and Wen (1997) for 2-dimensional SIT racks with single and dual-command cycles, respectively. They conclude that "The expected travel times are fairly insensitive to slight deviations in the optimal rack configuration".

- For dual-command cycles, where waiting of the crane on the conveyor to retrieve a load can be neglected, the optimal dimensions are $t_{c}^{*}=t_{c}^{*}=0.83 \sqrt[3]{V}, t_{c}^{*}=1.43 \sqrt[3]{V}$, and the optimal travel time is $1.78 \sqrt[3]{V}$.

A disadvantage of the method is that we assume that the rack is continuous. This simplification of reality is only justified if the number of storage positions is sufficiently large (see, for example, Graves et al. (1977) and Lee et al. (1999) ). The quality of the approximation of the real travel time depends on this.

We considered randomized storage only. Clearly, other storage policies (like class-based or dedicated storage) could be considered as well. This is an interesting direction for further research. 


\section{References}

Ashayeri, J., Heuts, H.C. and Veraart, H.C., A new approach for the determination of expected traveling time in an AS/RS under any assignment policy. In Progress in Material Handling Research: 1996, pp. 51-69, 1997 (Charlotte, NC: The Material Handling Industry of America).

Ashayeri, J., Heuts, R.M., Valkenburg, M.W.T., Veraart, H.C. and Wilhelm, M.R., A geometrical approach to computing expected cycle times for zone-based storage layouts in AS/RS. International Journal of Production Research, 2002, 40(17), 4467-4483.

Bozer, Y.A. and White, J.A., Travel-time models for automated storage/retrieval systems. IIE Transactions, 1984, 16, 329-338.

Bozer, Y.A. and White, J.A., Design and performance models for end-of-aisle order picking systems. Management Science, 1990, 36(7), 852-866.

Bozer, Y.A. and White, J.A., A generalized design and performance analysis models for endof-aisle order-picking systems. IIE Transactions, 1996, 28, 271-280.

Chang, D.T. and Wen, U.P., The impact of rack configuration on the speed profile of the storage and retrieval machine. IIE Transactions, 1997, 29, 525-531.

Chang, D.T., Wen, U.P. and Lin, J.T., The impact of acceleration/deceleration on travel-time models in class-based automated S/R systems. IIE Transactions, 1995, 27, 108-111.

De Koster, R. and Waals, F.A.J., Distrivaart. Praktijkboek Magazijnen Distributiecentra, 2005 (to appear).

Foley, R.D. and Frazelle, E.H., Analytical results for miniload throughput and the distribution of dual dates. IIE Transactions, 1991, 23, 273-281.

Foley, R.D., Frazelle, E.H. and Park, B.C., Throughput bounds for miniload automated storage/ retrieval systems. IIE Transactions, 2002, 34(10), 915-920. 
Foley, R.D., Hackman, S.T. and Park, B.C., Back-of-the-envelope miniload throughput bounds and approximations. IIE Transactions, 2004, 36, 279-285.

Graves, S.C., Hausman, W.H. and Schwarz, L.B., Storage-retrieval interleaving in automatic warehousing systems. Management Science, 1977, 23, 935-945.

Hausman, W.H., Schwarz, L.B. and Graves, S.C., Optimal storage assignment in automatic warehousing systems. Management Science, 1976, 22(6), 629-638.

Hu, Y.-H., Huang, S.Y., Chen, C., Hsu, W.-J., Toh, A.C., Loh, C.K. and Song, T., Travel time analysis of a new automated storage and retrieval system. Computers and Operations Research, 2005, 32, 1515-1544.

Hur, S., Lee Y.H., Lim, S.Y. and Lee M.H., A performance estimation model for AS/RS by M/G/1 queuing system. IIE Transactions, 2004, 46, 233-241.

Hwang, H. and Lee, S.B., Travel-time models considering the operating characteristics of the storage/retrieval system. International Journal of Production Research, 1990, 28(10), 1779-1789.

Johnson, M.E. and Brandeau, M.L., Stochastic modeling for automated material handling system design and control. Transportation Science, 1996, 30(4), 330-350.

Kim, J. and Seidmann, A., A framework for the exact evaluation of expected cycle times in automated storage systems with full-turnover item allocation and random service requests. Computer \& Industrial Engineering, 1990, 18(4), 931-952.

Kouvelis, P. and Papanicolaou, V., Expected travel time and optimal boundary formulas for a two-class-based automated storage/retrieval system. International Journal of Production Research, 1995, 33(10), 2889-2905.

Lee, H.F., Performance analysis for automated storage and retrieval systems. IIE Transactions, 1997, 29, 15-28. 
Lee, H.F., Tanchoco, J.M.A. and Chun, S.J., Performance estimation models for AS/RS with unequal sized cells. International Journal of Production Research, 1999, 37(18), 41974216.

Lee, H.L., Lee, M.H. and Hur L.S., Optimal design of rack structure with modular cell in AS/RS. International Journal of Production Economics, 2005 (to appear).

Meller, R.D. and Mungwattana, A., Multi-shuttle automated storage/ retrieval systems. IIE Transactions, 1997, 29(10), 925-938.

Pan, C.H. and Wang, C.H., A framework for the dual command cycle model in automated warehousing systems. International Journal of Production Research, 1996, 34(8), 20992117.

Park, Y.H. and Webster, D.B., Modeling of three dimensional warehouse systems. International Journal of Production Research, 1989a, 27(6), 985-1003.

Park, Y.H. and Webster, D.B., Design of class-based storage racks for minimizing travel time in a three dimensional storage system. International Journal of Production Research, 1989b, 27(9), 1589-1601.

Park, B.C., Foley, R.D. and Frazelle, E.H., Performance of miniload system with two-class storage. European Journal of Operational research, 2006, 170, 144-155.

Park, B.C., Foley, R.D., White, J.A. and Frazelle, E.H., Dual command travel times and miniload system throughput with turnover-based storage. IIE Transactions, 2003a, 35, 343-355.

Park, B.C., Frazelle, E.H. and White, J.A., Buffer sizing models for end-of-aisle order picking systems. IIE Transactions, 1999, 31(1), 31-38.

Park, B.C., Park, J.Y. and Foley, R.D., Carousel system performance. Journal of Applied Probability, 2003b, 40(3), 602-612. 
Potrč, I., Lerher, T., Kramberger, J. and Šraml, M., Simulation model of multi-shuttle automated storage and retrieval systems. Journal of Materials Processing Technology, 2004, 157-158, 236-244.

Rosenblatt, M.J. and Eynan, A., Deriving the optimal boundaries for class-based automatic storage/retrieval systems. Management Science, 1989, 35(12), 1519-1524.

Sarker, B.R. and Babu, P.S., Travel time models in automated storage/retrieval systems: A critical review. International Journal of Production Economics, 1995, 40, 173-184.

Van den Berg, J.P. and Gademann, A.J.R.N., Simulation study of an automated storage/retrieval system. International Journal of Production Research, 2000, 38, 13391356.

Wen, U.P., Chang, D.T. and Chen, S.P., The impact of acceleration/deceleration on traveltime models in class-based automated S/R systems. IIE Transactions, 2001, 33, 599-607. 


\section{List of Tables and Figures}
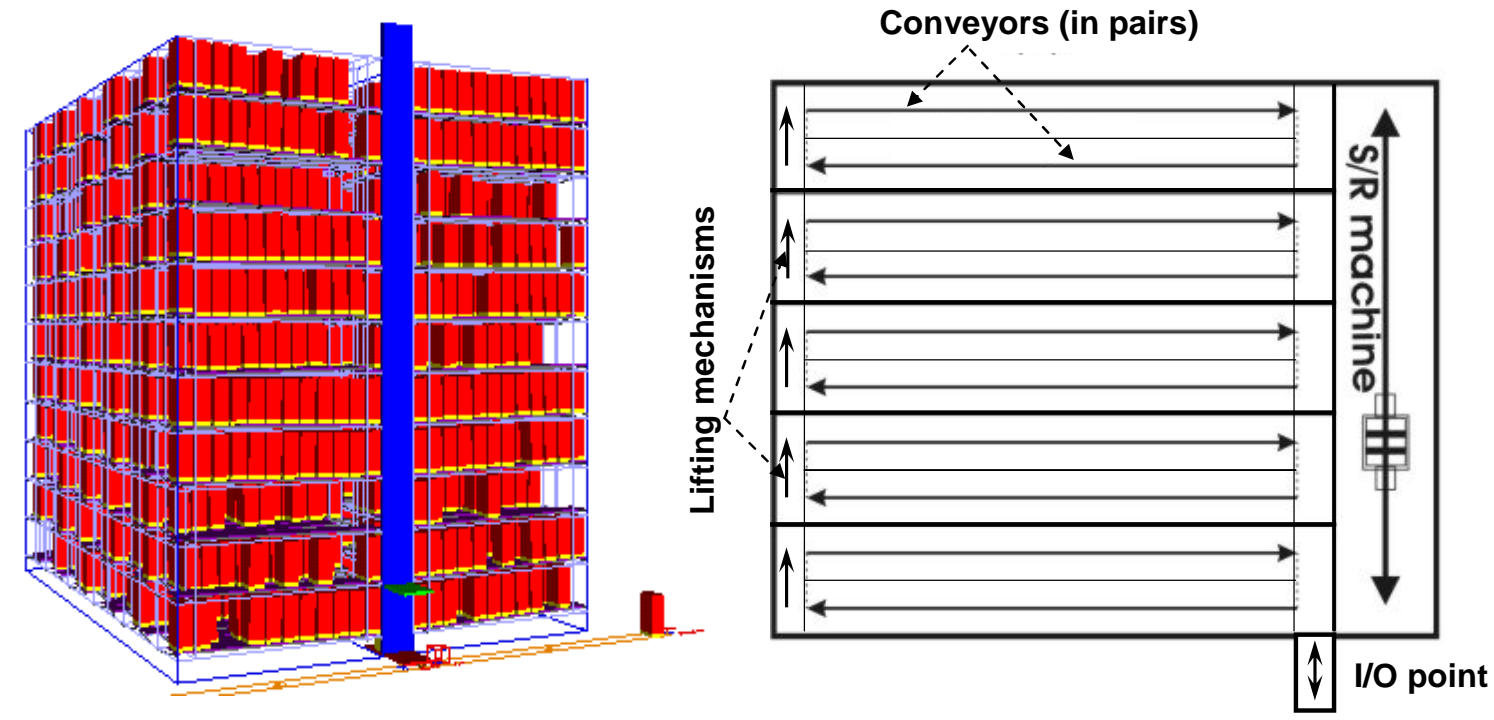

Figure 1 A compact S/RS with gravity conveyors for the depth movements

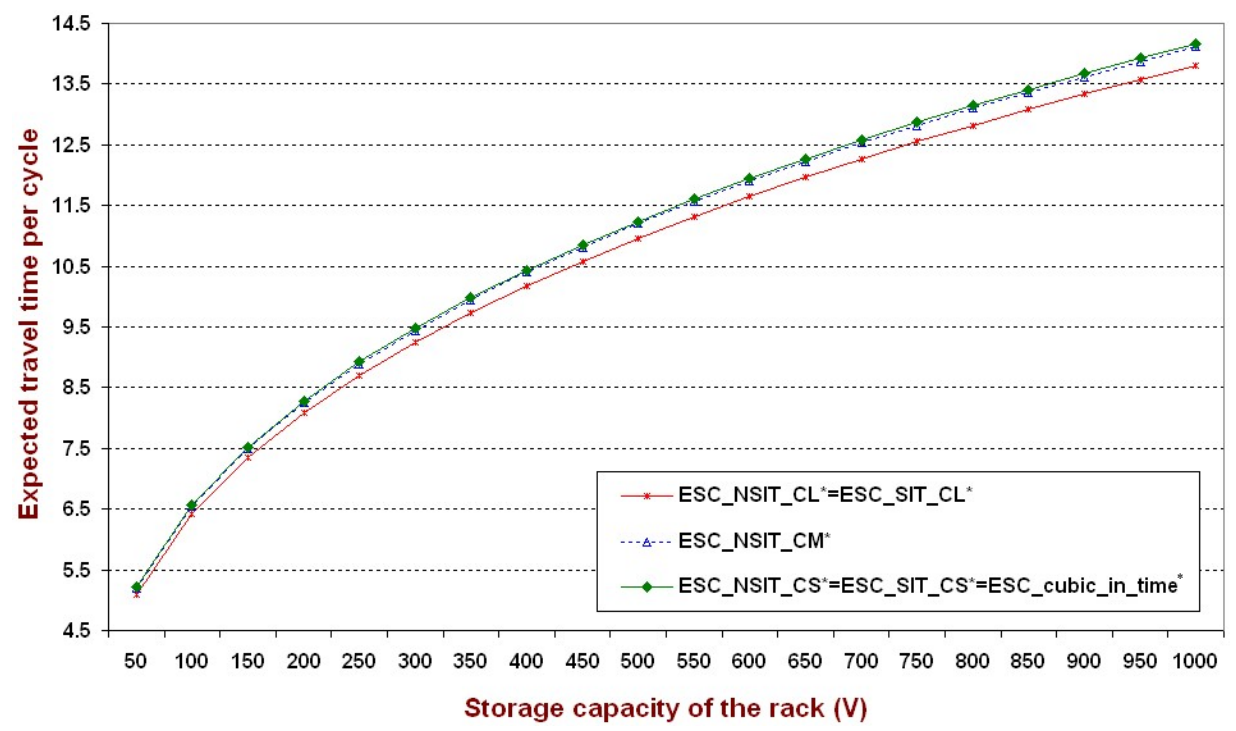

Figure 2 Comparison between optimal expected travel time of SIT and NSIT racks for different values of total storage capacity $V$ 


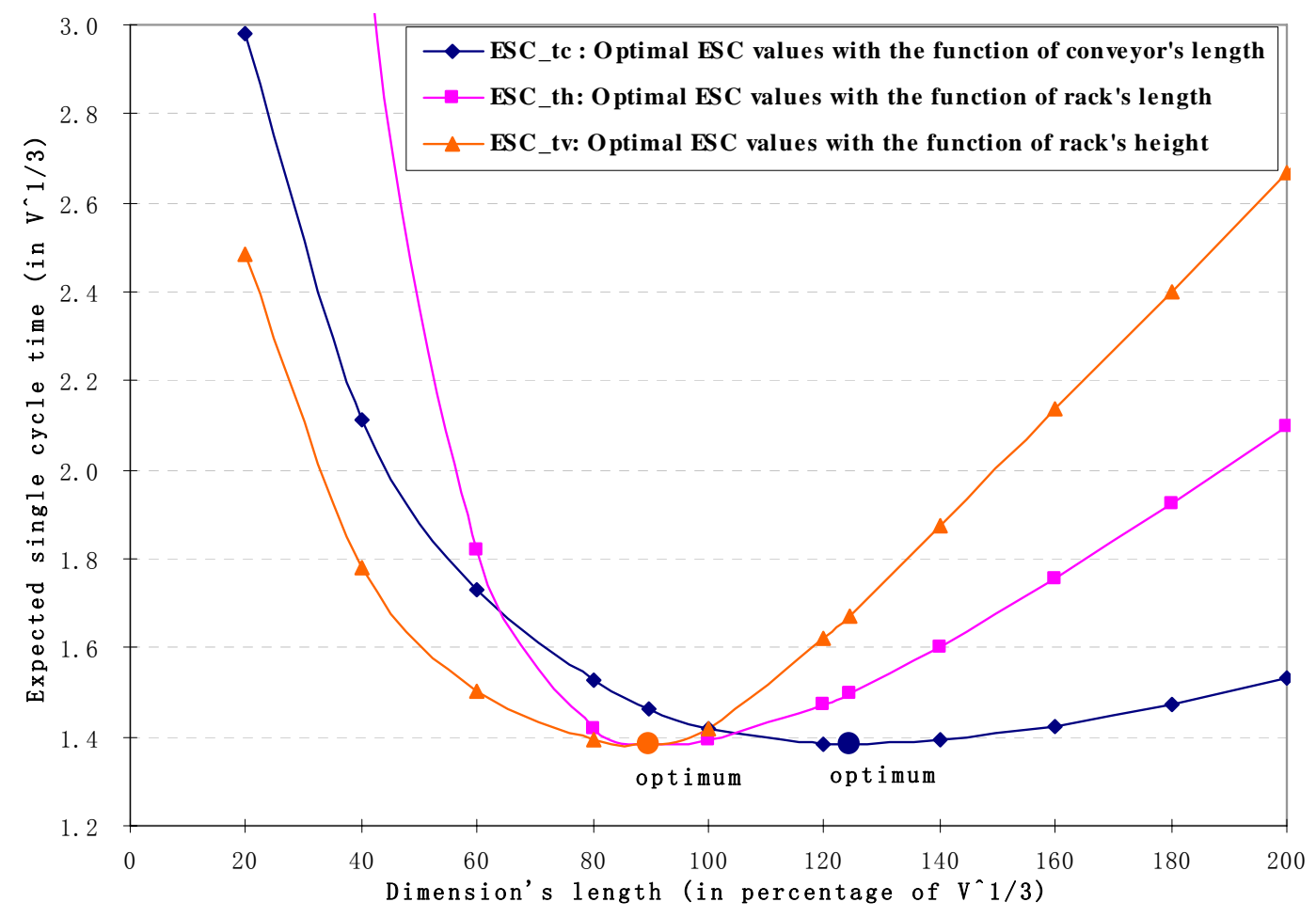

Figure 3 Optimal expected travel time when one of the three dimensions' lengths is fixed

Table 1 System parameters

\begin{tabular}{|c|c|c|c|}
\hline \multicolumn{3}{|c|}{ Total system capacity (V) } & 2000 pallets \\
\hline \multicolumn{3}{|c|}{ Storage policy } & Random storage \\
\hline \multirow{2}{*}{\multicolumn{2}{|c|}{$\begin{array}{l}\text { Pallet size in seconds } \\
\text { (width } \mathrm{x} \text { length } \mathrm{x} \text { height) }\end{array}$}} & Net & $0.4 \times 0.4 \times 2$ \\
\hline & & Gross & $0.5 \times 0.5 \times 2.17$ \\
\hline \multirow{2}{*}{$\begin{array}{l}\mathrm{S} / \mathrm{R} \\
\text { machine }\end{array}$} & \multicolumn{2}{|c|}{$\begin{array}{l}\text { Operating policy } \\
\text { Vertical speed }\left(s_{v}\right)\end{array}$} & $\begin{array}{l}\text { Single-command cycle } \\
0.8 \text { (meter per second) }\end{array}$ \\
\hline & \multicolumn{2}{|c|}{ Horizontal speed $\left(s_{h}\right)$} & 2.8 (meter per second) \\
\hline \multicolumn{3}{|c|}{ Conveyor speed $\left(s_{c}\right)$} & 1.6 (meter per second) \\
\hline
\end{tabular}




\section{Publications in the Report Series Research ${ }^{*}$ in Management}

\section{ERIM Research Program: "Business Processes, Logistics and Information Systems"}

2006

Smart Business Networks Design and Business Genetics

L-F Pau

ERS-2006-002-LIS

http://hdl.handle.net/1765/7319

Designing and Evaluating Sustainable Logistics Networks

J. Quariguasi Frota Neto, J.M. Bloemhof-Ruwaard, J.A.E.E. van Nunen and H.W.G.M. van Heck ERS-2006-003-LIS

http://hdl.handle.net/1765/7320

Design and Control of Warehouse Order Picking: a literature review

René de Koster, Tho Le-Duc and Kees Jan Roodbergen

ERS-2006-005-LIS

http://hdl.handle.net/1765/7322

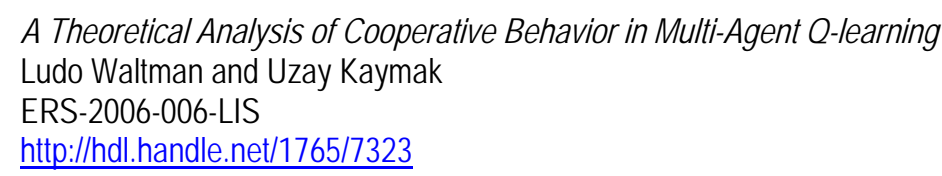

Supply-Chain Culture Clashes in Europe. Pitfalls in Japanese Service Operations M.B.M. de Koster and M. Shinohara

ERS-2006-007-LIS

http://hdl.handle.net/1765/7330

From Discrete-Time Models to Continuous-Time, Asynchronous Models of Financial Markets Katalin Boer, Uzay Kaymak and Jaap Spiering

ERS-2006-009-LIS

http://hdl.handle.net/1765/7546

Mobile Payments in the Netherlands: Adoption Bottlenecks and Opportunities, or... Throw Out Your Wallets Farhat Shaista Waris, Fatma Maqsoom Mubarik and L-F Pau

ERS-2006-012-LIS

http://hdl.handle.net/1765/7593

Hybrid Meta-Heuristics for Robust Scheduling M. Surico, U. Kaymak, D. Naso and R. Dekker ERS-2006-018-LIS

http://hdl.handle.net/1765/7644

VOS: A New Method for Visualizing Similarities between Objects

Nees Jan van Eck and Ludo Waltman

ERS-2006-020-LIS

http://hdl.handle.net/1765/7654

On Noncooperative Games, Minimax Theorems and Equilibrium Problems

J.B.G. Frenk and G. Kassay

ERS-2006-022-LIS

http://hdl.handle.net/1765/7809 
An Integrated Approach to Single-Leg Airline Revenue Management: The Role of Robust Optimization S. Ilker Birbil, J.B.G. Frenk, Joaquim A.S. Gromicho and Shuzhong Zhang

ERS-2006-023-LIS

http://hdll.handle.net/1765/7808

Optimal Storage Rack Design for a 3D Compact AS/RS with Full Turnover-Based Storage

Yu Yugang and M.B.M. de Koster

ERS-2006-026-LIS

http://hdl.handle.net/1765/7831

Optimal Storage Rack Design for a 3-dimensional Compact AS/RS

Tho Le-Duc, M.B.M. de Koster and Yu Yugang

ERS-2006-027-LIS

* A complete overview of the ERIM Report Series Research in Management: https://ep.eur.nl/handle/1765/1

ERIM Research Programs:

LIS Business Processes, Logistics and Information Systems

ORG Organizing for Performance

MKT Marketing

F\&A Finance and Accounting

STR Strategy and Entrepreneurship 